\title{
19
}

\section{Web tools and Web applications}

\author{
E. Pastor
}

Dep. de Ingeniería de Sistemas Telemáticos - UPM

ETSI Telecomunicación, Ciudad Universitaria s/n

28040 Madrid, Spain

e-mail: encarna@dit.upm.es

\begin{abstract}
This paper is a summary on the issues raised during the Working Conference concerning Web based learning systems and tools. Its content responds to the full range of written and spoken contributions at the Conference.
\end{abstract}

Keywords

Evaluation, Implementation phase, Organizational aspects, Web applications 


\section{INTRODUCTION}

The Word Wide Web is an emerging technology but already accounts for more Internet traffic than any other application, including email and simple file transfer. It increases the network capacities for information transfer and processing and it can support interactions between users over long distances.

Not surprisingly, the Web is increasingly being used as a platform to deliver education playing a central role in the development of new teaching and learning environments. Moreover, many institutions of higher education in the world are investing a large amount of resources in the Web as a vehicle to convey not only pedagogical material but also administrative information.

Confirming this trend, several papers presented at the Conference report on a range of Web based applications and tools, involving collaborative learning, individual learning, distribution of material and integration of facilities like, for example, simulators.

Web based applications relax some of the temporal and spatial constrains on communication while allowing for the presentation of multimedia information, collaborative work and provision for interaction. Although there is general agreement that Web applications have large potentials and benefits for education, there is no detailed view about how the Web should be used. Educators are still lacking appropriate didactical models to guide the realization of its potential. In this area, participants in the Conference pointed out several problems and some solutions.

Another important aspect raised by participants deals with the evaluation of Web based learning systems. It was noted that there is little regard for appropriate evaluation on the impact of new systems on the students' usual way of working as well as the effect on their already acquired study habits.

Finally, critical organizational issues to extend experiences to a real environment were mentioned like, for example, lack of infrastructure, some resistance of teachers to changes and rigid structures of current institutions.

All these issues will be summarized here as a result of discussions and written contributions.

\section{USING THE WEB}

The Web was originally designed as a mechanism for information access, not as an instrument to create systems for teaching and learning. In spite of the success of the Web, its technical capacity to carry multimedia materials and its facilities to build an extensible information base, it is not obvious how educational applications can take full advantage of the possibilities offered by the Web. Several solutions are possible and are evident in the systems presented at the Conference.

\section{- Organization of information}

Fernández-Manjón et al., in this volume, state that problems like lack of guidance in the access to information, disorientation as well as information overload affect 
seriously the usefulness of the Web as an educational tool. A new approach considers HTML as a tool that can help to organize and structure the content of documents according to pedagogical ideas. Using a richer and larger set of markup features it will be possible to apply pedagogical strategies in the presentation of the information.

\section{- Interactivity}

An important issue in distance teaching/learning is that of the evaluation, which could benefit the interactivity (self-learning assessment or automatic assessment (as addressed by Bedanokova and Teutsch in this volume) in the field of foreing-language learning). The incorporation of JAVA technology into Web browsers has emphasized the value of user interaction with a system. (Divjak; Tsironis and Neofotistos, both in this volume) suggests that the use of highly interactive systems based on JAVA enhances learning particularly in the field of science. JAVA is also the key for the development of virtual laboratories where students can directly interact with simulated artefacts (Llamas et al., in this volume) and be trained in virtual enviroments adapted to the particular target activity (Mc Daid et. al in this volume, which also elaborates on the production of training material addressing issues such as reusability or customisation).

\section{- Integration of tools}

Direct experimentation with learning materials like simulators or courseware is not sufficient (Adorni et al.; Llamas et al.; in this volume). Students need supervision by tutors as well as interactions with other students to discuss their own views and ideas. Some approaches consider that Web applications should integrate several resources to improve the effectiveness of learning such as hypertext material, simulated instruments for laboratory activities, tools for cooperative work, tools for self assessment and communication tools.

\section{- Software compatibility}

As a final technical remark, it is important to point out that the development of robust and stable Web based applications is sometimes limited by the rapid development of new software from different vendors using new technologies that are sometimes not compatible with previous environments. This fact represents a common problem to all Web based applications.

\section{- Resuability of corseware material}

Reusability could allow major benefits concerning the available learning material. Given the huge amount of such pieces of courseware a promising strategy could consist in organising the stuff coming from different sources into a large library of courseware (as proposed by M. Marolt and M. Privosnik in this volume).

\section{EVALUATION}

To assess the impact of Web based systems fully in the teaching/learning process a comprehensive evaluation of experiences is required. Usually the focus of the evaluation is on technical aspects of the system, usability or learning effectiveness. 
However it is also important to know how the students integrate the system into their usual way of working.

(Adorni et al., in this volume) suggest that the way the students interact with the technology might interfere with their already acquired habits. The authors argue that it is therefore important to collect and evaluate subjective information in order to determine which facilities of the system fit in with the students needs and which ones have been overlooked.

Experiences with the on-line use of a course module and its related tutorials showed that to exploit the possibilities of the system the students should change their habits to include more independent study activity and less reliance on immediate feedback from the tutor as in face to face interaction.

\section{IMPLEMENTATION PHASE: ORGANIZATIONAL ASPECTS}

Educators introduce new forms of learning and working when using Internet technologies and Web applications as part of the educational process.

According to the change of educational concepts, organizational structures and processes have to be adapted to the new learning and teaching situations. For example, a lecture-oriented course where teacher and students meet in a classroom requires a different organization from a course where students work at home and interact with the teacher by means of asynchronous or synchronous communication tools.

There are many organizational aspects to consider related to the implementation phase of a new technology in a specific educational setting. However, bounds imposed by current organizational or pedagogical models are sometimes ignored.

Several basic aspects were mentioned in the Conference discussions like availability of technology, cost of the system for the student, accessible infrastructure and acceptance of technology/changes by teachers.

Too frequently such basic aspects are overlooked and thus, for example, the availability of the newest technologies is presupposed.

To overcome these weak points, a careful strategic plan for the implementation phase has to be designed. One of the aims would be to harmonize new requirements with current organizational structures and users' capabilities in a specific setting.

\section{BIOGRAPHY}

Encarna Pastor is Associate Professor at the Departamento de Ingenieria de Sistemas Telemáticos of the Universidad Politécnica de Madrid. She received the Ph.D. degree on Computer Science from the same University in 1988. For the last years she has been involved in R\&D activities related to telematics applications, communication architectures and computer-supported cooperative work. Current interest research fields include distributed multimedia systems and collaborative learning. 